\title{
Increasing the efficiency of material removal using dual laser micromachining
}

\author{
Osama Alkhawaldeh ${ }^{1}$ (D) $\cdot$ Jeremy Coupland ${ }^{1}$ (D) $\cdot$ Lewis C. R. Jones ${ }^{1}$ (D)
}

Received: 27 January 2020 / Accepted: 26 March 2020 / Published online: 23 April 2020

(C) The Author(s) 2020

\begin{abstract}
A continuous wave melting laser combined with a nanosecond ejection laser has been shown to improve the material removal efficiency by a factor of 2 to 8 compared with laser ablation processes reported in the literature. The decrease in the energy required for the combined lasers is primarily due to the optimisation of the irradiation time in the melting process, which is responsible for the majority of the total energy. For the laser used in this study, the optimal interaction time corresponding to the highest melting efficiency was found at 9-ms melting time, and this value is compared with results derived from a onedimensional heating model. Metallurgical images of only melting and the produced hole after introducing the ejection pulse for the most efficient melting were presented as evidence of melt ejection. The results show that approximately $90 \%$ of the melt pool is ejected with little redeposited material at the periphery of the hole.
\end{abstract}

Keywords Beam-matter interaction $\cdot$ Short pulsed lasers $\cdot$ Laser material processing $\cdot$ Laser melting

\section{Nomenclature}

A $\quad$ Area of the laser beam spot $\left(\mathrm{m}^{2}\right)$

$c \quad$ Specific heat capacity $(\mathrm{J} / \mathrm{kg} \mathrm{K})$

$E \quad$ Energy absorbed by the surface

$E_{0}$

$E_{\text {eject }}$

$E_{\mathrm{m}}$

$E_{\text {melt }}$

$E_{\text {melt_exp }}$

$E_{\text {melt_theory }}$

$E_{\text {total_exp }}$

$A$, to the melting temperature

in the period $0<t \leq t_{\mathrm{m}}(\mathrm{J})$

$(\mathrm{J} / \mathrm{kg})$ in the melting process $E=I A\left(t-t_{\mathrm{m}}\right),(\mathrm{J})$

Energy required to bring a surface area,

Specific energy to eject the liquid material

(the minimum specific energy required

to overcome the surface energy) $(\mathrm{J} / \mathrm{kg})$

Melting specific energy (lossless model)

Specific energy required to form a melt pool through surface conduction heating $(\mathrm{J} / \mathrm{kg})$

Specific energy for experimental melting $(\mathrm{J} / \mathrm{kg})$

Specific energy for theoretical melting $(\mathrm{J} / \mathrm{kg})$

Experimental specific energy for DLM method results $(\mathrm{J} / \mathrm{kg})$

Lewis C. R. Jones

L.Jones@lboro.ac.uk

1 Wolfson School of Mechanical, Electrical and Manufacturing

Engineering, Loughborough University,

Loughborough, Leicestershire LE11 3TU, UK
$E_{\text {total } \_ \text {theory }}$ Theoretical specific energy for DLM method, $E_{\text {total } \_ \text {theory }}=E_{\text {melt }}+E_{\text {eject }}(\mathrm{J} / \mathrm{kg})$

$E_{\mathrm{v}} \quad$ Vaporisation specific energy $(\mathrm{J} / \mathrm{kg})$

I Absorbed peak laser irradiance $\left(\mathrm{W} / \mathrm{m}^{2}\right)$

$I_{0} \quad$ Peak laser irradiance $\left(\mathrm{W} / \mathrm{m}^{2}\right)$

$I_{\text {absorbed_eject }}$ Absorbed irradiance of the ejection beam $\left(\mathrm{W} / \mathrm{m}^{2}\right)$

$I_{\text {eject }} \quad$ Irradiance of the ejection beam $\left(\mathrm{W} / \mathrm{m}^{2}\right)$

$k \quad$ Thermal conductivity at room temperature (W/m K)

$k_{1} \quad$ Mean thermal conductivity in the liquid region $(\mathrm{W} / \mathrm{m} \mathrm{K})$

$k_{2} \quad$ Mean thermal conductivity in the solid region (W/m K)

Maximum DLM hole depth (m)

Latent heat of melting $(\mathrm{J} / \mathrm{kg})$

Latent heat of vaporisation $(\mathrm{J} / \mathrm{kg})$

Mass of melted material $(\mathrm{kg})$

Absorbed laser power (W)

Laser power (W)

Reflection coefficient of ejection laser

Reflection coefficient of melting laser

Theoretical melt depth (Cohen's model) (m)

Dimensionless melt depth (Cohen's model)

$[S]$

$S_{\max }$
Maximum melt depth when

surface vaporisation occurs (m) 
material. In the following, we will refer to this process as dual laser micromachining (DLM). Fox [23] was first to report DLM using a continuous wave (CW) laser with a pulsed laser to cut 1-mm-thick 316 stainless steel. Prior to the complete breakthrough of the $\mathrm{CW}$ laser, a single $25-\mathrm{ns}$ pulse, peak irradiance of $10^{9} \mathrm{~W} / \mathrm{cm}^{2}$, was introduced to the surface to push out the molten material. Fox found a decrease of irradiation time by more than a factor of two in addition to the increase in the quality as using $\mathrm{CW}$ only. Other DLM experiments have demonstrated improvements in laser drilling material removal rates in stainless steel by up to an order of magnitude [24-26]. However, there is a considerable range of results both in quality and efficiency. In this paper, we consider these characteristics for the first time. Theoretical and experimental results are compared with conventional laser vaporisation process, found in the literature, and improvement in the material removal rates and machining quality are discussed. In addition, sectioning of the melt pool and machined workpiece features provides some useful insight into the ejection mechanism.

\section{Theory}

The potential benefits of DLM are made clear by comparing the energy required to remove material by direct vaporisation (ablation) to that required to melt and remove the same volume of material by mechanical means.

Let us first consider the removal of material from the surface of a homogenous substrate under the assumption of uniform heating and no heat loss. If it is assumed that the specific heat capacity, $c$, is temperature-independent and taken at room temperature, the specific energy, $E_{\mathrm{v}}$, required to vaporise the material is:

$E_{\mathrm{v}}=c\left(T_{\mathrm{v}}-T_{0}\right)+L_{\mathrm{m}}+L_{\mathrm{v}}$

where $L_{\mathrm{m}}$ and $L_{\mathrm{v}}$ are the latent heat capacities of melting and vaporisation, respectively, $T_{\mathrm{v}}$ is the vaporisation temperature, and $T_{0}$ is room temperature. Similarly, the specific energy, $E_{\mathrm{m}}$, required to melt the material is given by:

$E_{\mathrm{m}}=c\left(T_{\mathrm{m}}-T_{0}\right)+L_{\mathrm{m}}$

where $T_{\mathrm{m}}$ is the melting temperature.

Taking room temperature, $T_{0}=294 \mathrm{~K}$ and using the physical properties for 316 stainless steel shown in Table 1, Eqs. (1) and (2) give $E_{\mathrm{v}}=9.14 \times 10^{6} \mathrm{~J} / \mathrm{kg}$ and $E_{\mathrm{m}}=9.76 \times 10^{5} \mathrm{~J} / \mathrm{kg}$, respectively. For typical values such as these, it is noted that the specific energy $E_{\mathrm{v}}$ is dominated by the latent heat of vaporisation, while the specific energy $E_{\mathrm{m}}$ is largely determined by the energy necessary to raise the layer to the melting temperature, such that:
$\frac{E_{\mathrm{v}}}{E_{\mathrm{m}}} \sim \frac{L_{\mathrm{v}}}{c\left(T_{\mathrm{m}}-T_{0}\right)} \sim 10$

These basic calculations suggest that material removal via melt ejection is potentially around ten times more efficient than vaporisation; however, Eqs. (1), (2), and (3) represent the minimum energy required to remove material and are based on lossless heating with no regard to the heat source or ejection process and do not represent the complex laser process sufficiently well. If an alternative mechanical ejection mechanism is used on the melt pool, then energy could be saved compared with pure vaporisation.

The heat lost to the substrate can be estimated from the work of Cohen [29]. Using the analogue computing facilities available to him in 1967, Cohen investigated the propagation of the liquid/solid boundary for the case of a semi-infinite body subjected to constant heat input. He showed that in the period following surface melting and before surface vaporisation, the melt pool depth increased in an approximately linear manner until the surface reached the vaporisation temperature after which the melting process slowed substantially. Although, the non-linear, coupled differential equations governing the propagation can be solved more precisely [30], the graphical data provided by Cohen and the resulting empirical relationships are more useful as a means to estimate the efficiency of the melting process. Cohen's results allow us to estimate the melt depth, $S$ :

$S=\frac{0.14 I\left(t-t_{\mathrm{m}}\right)}{\rho L_{\mathrm{m}}}$

where $I$ is the absorbed irradiance defined by absorbed power, $P$, per unit area, $A, t$ is the time required to achieve the melt depth from the start of the laser material irradiation, $t_{\mathrm{m}}$ is the time required for the surface to reach the melting temperature given in Eq. (5), and $\rho$ is the material density at room temperature. Equation (4) is valid for time $t \leq t_{\mathrm{v}}$, where $t_{\mathrm{v}}$ is the time when the surface begins to vaporise.

$t_{\mathrm{m}}=\pi k \rho c\left[\frac{T_{\mathrm{m}}-T_{0}}{2 I}\right]^{2}$

where $k$ is the thermal conductivity at room temperature.

The constant 0.14 in Eq. (4) represents the actual energy used to create the melt pool, accounting for losses via conduction, and has been derived from Cohen's results for the thermophysical properties of 316 stainless steel used in this paper.

It is noted that Cohen's analysis assumes that the material's properties in the molten phase are identical to those of the solid phase at room temperature except for the thermal conductivity. A ratio $k_{1} / k_{2}$ was used, where $k_{1}$ and $k_{2}$ are the mean 
Table 1 Thermophysical properties of 316 stainless steel

\begin{tabular}{|c|c|c|c|}
\hline Property & Symbol & Unit abbreviation & Value \\
\hline Melting temperature [27] & $T_{\mathrm{m}}$ & $\mathrm{K}$ & 1700 \\
\hline Vaporisation temperature [27] & $T_{\mathrm{v}}$ & $\mathrm{K}$ & 3090 \\
\hline Latent heat of melting [27] & $L_{\mathrm{m}}$ & $\mathrm{J} / \mathrm{kg}$ & $2.7033 \times 10^{5}$ \\
\hline Latent heat of vaporisation [27] & $L_{\mathrm{v}}$ & $\mathrm{J} / \mathrm{kg}$ & $7.46417 \times 10^{6}$ \\
\hline Density (at $294 \mathrm{~K}$ ) [27] & $\rho$ & $\mathrm{kg} / \mathrm{m}^{3}$ & 7956.9 \\
\hline Thermal conductivity $^{\mathrm{a}}$ [27] & $k$ & $\mathrm{~W} / \mathrm{m} \mathrm{K}$ & $\begin{array}{l}13.87 \text { (at } 294 \mathrm{~K} \text { ) } \\
24.96 \text { (at } 1000 \mathrm{~K} \text { ) } \\
20.12 \text { (at } 2350 \mathrm{~K} \text { ) }\end{array}$ \\
\hline Specific heat capacity (at 294 K) [27] & $c$ & $\mathrm{~J} / \mathrm{kg} \mathrm{K}$ & 502 \\
\hline Surface tension coefficient (at $1823 \mathrm{~K}$ ) [28] & $\gamma$ & $\mathrm{J} / \mathrm{m}^{2}$ & 1.784 \\
\hline
\end{tabular}

${ }^{a}$ Thermal conductivity is presented at different temperatures as in this paper we will show its importance in the calculation of the theoretical melting thermal conductivities in the liquid and solid regions, respectively. Although this is not strictly true, the density, specific heat capacity, and thermal conductivity are significantly temperature-dependent with a discontinuity at the melting point. To calculate the ratio $k_{1} / k_{2}$, the mean thermal conductivities in the liquid and solid regions were taken for 316 stainless steel to be $24.96 \mathrm{~W} / \mathrm{m} \mathrm{K}$ at $1000 \mathrm{~K}$ and 20.12 at $2350 \mathrm{~K}$ respectively [27] to give $k_{1} / k_{2}=0.81$ and the following approximations were made from the nearest of Cohen's results $\left(k_{1} / k_{2}=0.75\right)$.

The heat loss constant is generated from Fig. 8 in Cohen, which shows the results of dimensionless depth, $[S]$, as a function of for several values of the ratios $Y$ and $k_{1} / k_{2}$. Where $=t / t_{\mathrm{m}}, Y$ is the ratio between latent heat of melting to the specific energy required to raise the material temperature to melting temperature: $Y=L_{\mathrm{m}}$ / $\left(c\left(T_{\mathrm{m}}-T_{0}\right)\right)$. From the thermal properties of 316 stainless steel shown in Table 1, it was found that $Y=0.38$. To optimise the energy use in Eq. (4), the maximum melt depth before surface vaporisation, $S_{\max }$, was identified from Fig. 8 in Cohen's analysis. For our material properties, the dimensionless surface temperature $[T]$ given by $[T]=40\left(T-T_{0}\right) /\left(T_{\mathrm{m}}-T_{0}\right)=80$ where $T$ is the surface temperature. Using this data, it is evident that the surface temperature reaches the vaporisation point at a time, $t_{\mathrm{v}} \approx$ $3 t_{\mathrm{m}}$.

We now consider the energy required to create the melt pool. Let the energy required to bring a surface area, $A$, to the melting temperature in the period $0<t \leq t_{\mathrm{m}}$ be $E_{0}$. In the time interval that follows, $t_{\mathrm{m}}<t<t_{\mathrm{v}}$, the energy absorbed by the surface is $E=I A\left(t-t_{\mathrm{m}}\right)$, and the melted mass is given by $m=A \rho S$. Accordingly, the specific energy $E_{\text {melt }}$ required to create the melt pool is given by:

$E_{\mathrm{melt}}=\frac{E_{0}+I A\left(t-t_{\mathrm{m}}\right)}{A \rho S}$
Substituting from Eqs. (4) and (5):

$E_{\text {melt }}=\frac{\pi}{4} \frac{k c}{S I}\left[T_{\mathrm{m}}-T_{0}\right]^{2}+7.14 L_{\mathrm{m}}$

In comparison with the lossless case described by Eq. (2), we note that the terms in Eq. (7) can be associated with preand post-melting in a similar way. The first term is the specific energy required to bring the surface to the melting temperature; the second term is simply a multiple of the latent heat of melting. An increase in desired melt depth and/or irradiance will reduce the value of the first term, reducing the proportion of total energy used to raise the surface to $T_{\mathrm{m}}$. As noted before, for the case of 316 stainless steel discussed in this paper, under constant heating, the time taken to increase the surface temperature from room temperature to vaporisation is approximately three times that required to melt the surface and the first term is minimised when $S=S_{\max }=0.14 I\left(t_{\mathrm{v}}-t_{\mathrm{m}}\right) / \rho L_{\mathrm{m}}$ where it is found,

$E_{\text {melt }} \approx 11 L_{\mathrm{m}}$

Returning to the lossless case of Eq. (2), we note that the first term is the energy required to bring a unit mass to the melting temperature and consequently has a finite value and for 316 stainless steel $c\left(T_{\mathrm{m}}-T_{0}\right) \approx 2.6 L_{\mathrm{m}}$. Combining the terms in Eq. (2) in a similar manner, we note that in this idealised case,

$E_{\mathrm{m}} \approx 3.6 L_{\mathrm{m}}$

We, therefore, conclude that the specific energy required to form a melt pool through surface conduction heating, $E_{\text {melt }}$, of 316 stainless steel is approximately three times that required to do so by direct lossless heating, $E_{\mathrm{m}}$.

Finally, we must consider the specific energy to eject the liquid material, $E_{\text {eject }}$ to find the total specific energy for the DLM process, $E_{\text {total theory }}=E_{\text {melt }}+E_{\text {eject }}$. In theory, the 
minimum energy is that required to overcome the surface energy, $\gamma$, at the liquid-solid interface to separate the liquid and create new surfaces such that,

$E_{\text {eject }}=\frac{2 \gamma}{S \rho}$

For stainless steel, $\gamma=1.784 \mathrm{~J} / \mathrm{m}^{2}$ at $1823 \mathrm{~K}$ and assuming a melt depth of $10 \mu \mathrm{m}, E_{\text {eject }}=45 \mathrm{~J} / \mathrm{kg}$. At least, in theory, the energy necessary to eject material can be considered to be negligible in comparison with the specific energy to form the melt pool $\left(E_{\text {melt }}=1 \times 10^{7} \mathrm{~J} / \mathrm{kg}\right)$. In DLM, this energy is provided by the nanosecond pulse from a second laser which rapidly increases the surface temperature, vaporises a thin layer (vaporisation depth $<<$ melt depth) and in doing so, imparts a pressure equal to the vapour pressure at the elevated temperature [31]. Although this process is less than ideal, as we will see later, the energy required by the ejection laser remains a small fraction of the total.

The trends showing the energy required for lossless vaporisation and melting of a given mass are shown alongside melting from Cohen's theory, where $I=13 \mathrm{~kW} / \mathrm{cm}^{2}$, (Eqs. (1), (2), and (7) respectively) are plotted in Fig. 1. It is noted that the lossless curves pass through the origin (Eqs. (1) and (2)) whereas the Cohen's theory has an offset corresponding to the energy lost bringing the surface temperature to the melting point. Figure 1 shows that for energies below the cross-over point $\mathrm{A}$, the energy required to vaporise a given mass of material is less than that required to melt the same quantity of

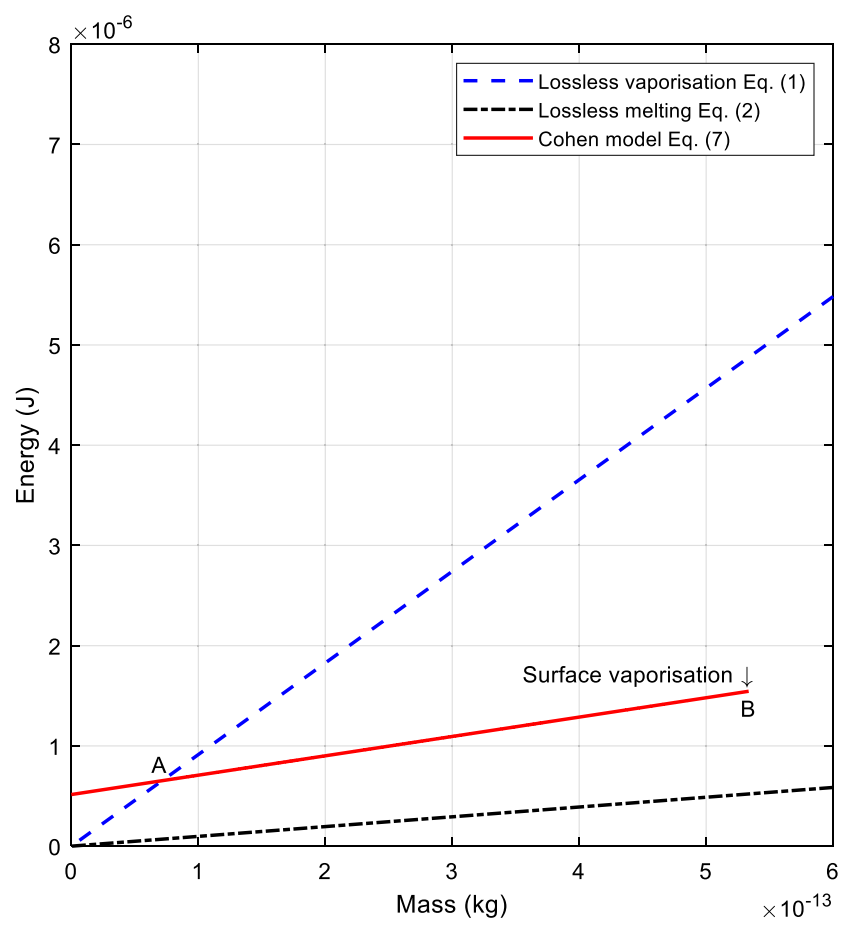

Fig. 1 Comparing energy consumption for mass removal by lossless vaporisation, lossless melting, and Cohen's theoretical melting models for 316 stainless steel material. Above point A, it becomes progressively more efficient to remove material by melting rather than vaporisation even if the latter is assumed lossless. The maximum efficiency occurs when the surface temperature has just reached the vaporisation point at time $t_{\mathrm{v}}$; the point at which Cohen's theory is no longer valid (point $B$ ).

Finally, we note that ablative removal of material by way of vaporisation is significantly less efficient than that suggested by Eq. (1) and depends strongly on pulse energy and duration $[32,33]$. Experimentally it has been shown that in practice, ablation processes using nanosecond pulsed lasers are at best $48 \%$ efficient [32]. The one-dimensional model presented has described a single pulse surface heating, similar to a piercing, drilling, or micromachining process. The following section explores these findings experimentally and compares the efficiency of DLM with ablative removal of material.

\section{Method}

This section presents work to implement the DLM process in practice and compares the energy efficiency with conventional ablative machining found in the literature. The quality of the DLM process has also been assessed using metallurgical techniques. Three experimental setups were investigated to investigate the efficiency of DLM in practice. First molten pool generation using only the $\mathrm{CW}$ laser beam was explored to investigate how the melt pool develops with time. The effect of nanosecond pulsed laser on the material surface was then considered to examine its machining capability. Finally, the combination of both lasers in the DLM method was investigated as a means to achieve liquid phase ejection and optimum efficiency.

Two lasers were used in this study (Table 2). A CW fibre laser, the "melting laser" to create a molten pool; and a Qswitched Nd:YAG laser, the "ejection laser", provided the necessary impulse required to eject the molten material. An SPI G4 Fibre Laser Module, with a wavelength of $1064 \mathrm{~nm}$, was used for melting in $\mathrm{CW}$ mode. The power of the laser was measured to be $18.9 \mathrm{~W}$ using a Coherent LM-200 power meter. The beam is focused using a galvanometer scanning head fitted with a $160-\mathrm{mm}$ focal length F-theta lens. The beam was defocused to enlarge the beam size to provide a constant peak irradiance of approximately $35 \mathrm{~kW} / \mathrm{cm}^{2}$. This laser irradiance is in the conduction-limited mode without vaporisation in the melting process [34]. A Q-switched Continuum Surelite $\mathrm{Nd}$ :YAG laser with a 4-6-ns pulse width, 532-nm wavelength, and $10-\mathrm{Hz}$ repetition rate was used for melt ejection. The pulse energy of $50 \mathrm{~mJ}$ was measured using Gentec-EO Model SOLO 2 (R2).

A set of dielectric mirrors were used to deliver the Nd:YAG laser beam to the same position as the fibre laser beam spot on the target workpiece surface. A lens of focal length $120 \mathrm{~mm}$ 
Table 2 Specifications of the lasers used

\begin{tabular}{lll}
\hline Laser & Melting laser (fibre) & Ejection laser (Nd:YAG) \\
\hline Wavelength & $1064 \mathrm{~nm}$ & $532 \mathrm{~nm}$ \\
Pulse duration & $\mathrm{CW}$ & $4-6 \mathrm{~ns}$ \\
Output power & $18.9 \mathrm{~W}$ & - \\
Collimated beam diameter & - & $7 \mathrm{~mm}$ \\
$\mathrm{M}^{2}$ & 1.6 & - \\
Focus size & $131 \mu \mathrm{m}$ (radius, $1 / \mathrm{e})$ & Elliptic of $400 \mu \mathrm{m}$ major and 300 \\
& & $\mu \mathrm{m}$ minor axes \\
Irradiance & $35 \mathrm{~kW} / \mathrm{cm}^{2}$ & $10 \mathrm{GW} / \mathrm{cm}^{2}$ \\
Pulse energy & - & $50 \mathrm{~mJ}$ \\
Fluence & - & $53 \mathrm{~J} / \mathrm{cm}^{2}$ \\
Focal length & $160 \mathrm{~mm}$ & $120 \mathrm{~mm}$ \\
Repetition rate & - & $20 \mathrm{~Hz}$ \\
\hline
\end{tabular}

was used to focus the ejection laser beam. The focal plane position could be manually adjusted by a Newport precision stage until achieving the minimum Nd:YAG laser spot size. The fibre laser illuminated the object at normal incidence while for practical convenience, the ejection laser beam was focused with an incidence angle of $40^{\circ}$ that makes the beam on the workpiece becomes an elliptic shape whose major and minor axes are 400 and $300 \mu \mathrm{m}$ respectively, producing a laser fluence of $53 \mathrm{~J} / \mathrm{cm}^{2}$ that is above the vaporisation threshold for metals [35].

The fibre laser was internally triggered to provide a $10-\mathrm{Hz}$ pulse stream of variable pulse width. The light scattered from the workpiece surface was detected by a PIN photodiode, with the rise time of $20 \mathrm{~ns}$ and the spectral range of sensitivity 400 1100-nm wavelength that encompasses the fibre laser wavelength $1064 \mathrm{~nm}$. The signal from the photodiode was sent to a pulse generator to trigger the ejection laser with a programmable delay. The experimental setup of the time synchronisation is illustrated in Fig. 2.

Using this setup, the ejection pulse is triggered at the end of the melting process. The actual delay time is defined as the interval between the start of the melting and ejection pulse as monitored by the photodiode and measured using an oscilloscope, this is equal to the total melting time. In these experiments, the workpiece is mounted on a stationary workstation stage.

The melting process was conducted at a power of $18.9 \mathrm{~W}$, and 5- to 68.1-ms melting time range to determine the melt depth. A 316 stainless steel with 3-mm thicknesses was used in this study to make suitable comparisons to literature works on conventional laser processing efficiency [32, 33]. To prevent oxidation, all the experiments in this study were carried out with argon shielding gas. The argon gas was introduced into an open-top box where the workpiece was located. The optimum gas flow rate and the pressure of $4 \mathrm{~L} / \mathrm{min}$ and $1.5 \mathrm{bar}$, respectively, were found to achieve the minimum oxygen percentage of $3 \%$ at the workpiece surface, verified using a Kane 510 single gas analyser.

In each case, the geometry and metallurgical features of melt cross-sections were analysed using an optical microscope. All images were taken from central cross-sections, and in each show the maximum melt depth achieved. Workpieces were prepared for microstructural analysis by mounting using conducting bakelite, mechanically grinding using series of 320,600, 1200, and 4000 grit SiC grades, polishing using 9, 3, and $0.050 \mu \mathrm{m}$ diamond suspension, and etching using Kalling's No. 2 for approximately 5 s. The recast molten material and $\mathrm{HAZ}$ are used in the analysis as a quality indicator.

\section{Results}

The following section presents the results of surface treatment using the melting laser only, the (Nd:YAG) ejection laser only, and both lasers combined in the DLM process.

\subsection{Effect of melting without ejection}

Using the fibre melt laser, operating at maximum power $(18.9 \mathrm{~W})$, the onset of surface melting was found to occur with at an irradiation duration of $5 \mathrm{~ms}$. As has been noted by [36], with knowledge of the material properties, this data point can be used to calculate the peak irradiance $I_{0}$ and the radius of the laser beam, w. Rearranging Eq. (5), the absorbed peak irradiance $I$ required to bring the surface up to the melting temperature under the assumption of uniform heating is given by,

$I=\sqrt{\frac{\pi k \rho c\left(T_{\mathrm{m}}-T_{0}\right)^{2}}{4 t_{\mathrm{m}}}}$ 
Fig. 2 Schematic of the DLM setup shows the synchronisation between the two lasers

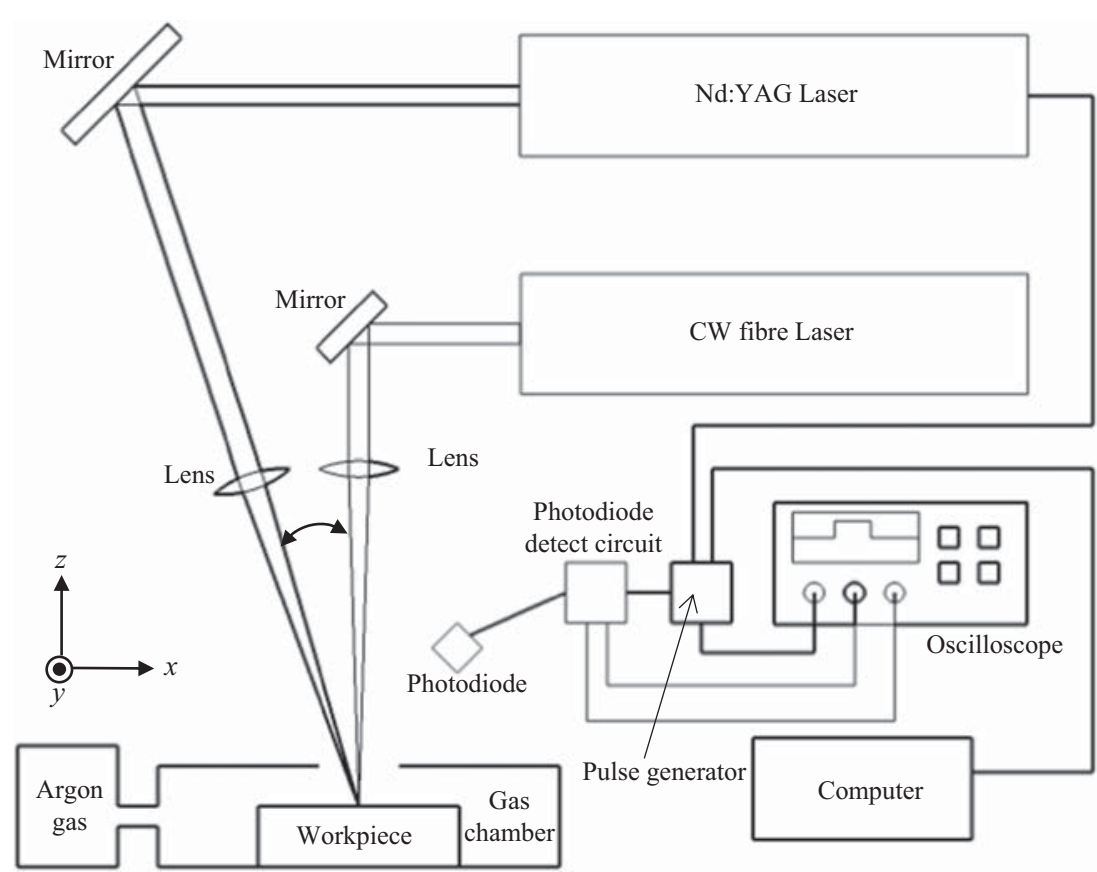

Using the material properties for 316 stainless steel from Table 1, it is found that the absorbed irradiance is approximately $13 \mathrm{~kW} / \mathrm{m}^{2}$. The corresponding laser irradiance can be calculated using knowledge of the reflection coefficient, $r_{\text {melt }}$, such that,

$I_{0}=\frac{I}{\left(1-r_{\text {melt }}\right)}$

The reflectance values used in the calculations are taken from measurements by Bergström et al. [37] for 316 stainless steel. These results are valid for Nd: YLF (1053 and $527 \mathrm{~nm}$ ) and Nd:YAG (1064 and $532 \mathrm{~nm}$ ) lasers at room temperature. The roughness of the workpieces used in this paper $\left(S_{\mathrm{a}}, 0.142\right.$ and $S_{\mathrm{q}}, 0.194 \mu \mathrm{m}$ ), measured using an Alicona Infinite-Focus microscope, is similar to those used by Bergström et al. $\left(S_{\mathrm{a}}\right.$, $0.15 \mu \mathrm{m}$ and $\left.S_{\mathrm{q}}, 0.19 \mu \mathrm{m}\right)$. Although it is known that reflectivity decreases with temperature increase [38], the exact value for the ejection pulse on the melt pool is unknown, and room temperature values will be assumed. The reflectivity values used were $62.8 \%$ for the melting laser and $56.2 \%$ for the ejection laser. Using $r_{\text {melt }}=0.628$, the peak irradiance of the melting laser was found to be $35 \mathrm{~kW} / \mathrm{cm}^{2}$. If it is assumed that the laser beam has a Gaussian profile then the beam radius, at a position where the intensity falls to $1 /$ e times, its maximum value is given by,

$w=\sqrt{\frac{P_{0}}{\pi I_{0}}}$

where $P_{0}$ is the total power transmitted by the beam.

From the power measurements described in section 3 and $I_{0}=35 \mathrm{~kW} / \mathrm{cm}^{2}$, it is found that the beam radius is $w=$
$131 \mu \mathrm{m}$. The focused beam size was verified by optical measurement of the spot created on laser mode burn paper [39].

The melting process was conducted on a wide range of melting times to achieve melt pools. Cross-sections of each individual melt time were taken and measured by optical microscope; Fig. 3 shows that the melt pools were created with 6-68.1-ms melting times to a maximum melt depth of $31 \mu \mathrm{m}$. The theoretical results, calculated using the laser irradiance $35 \mathrm{~kW} / \mathrm{cm}^{2}$ above, align with the experimental melt data at low melting time values. However, after that, the experimental

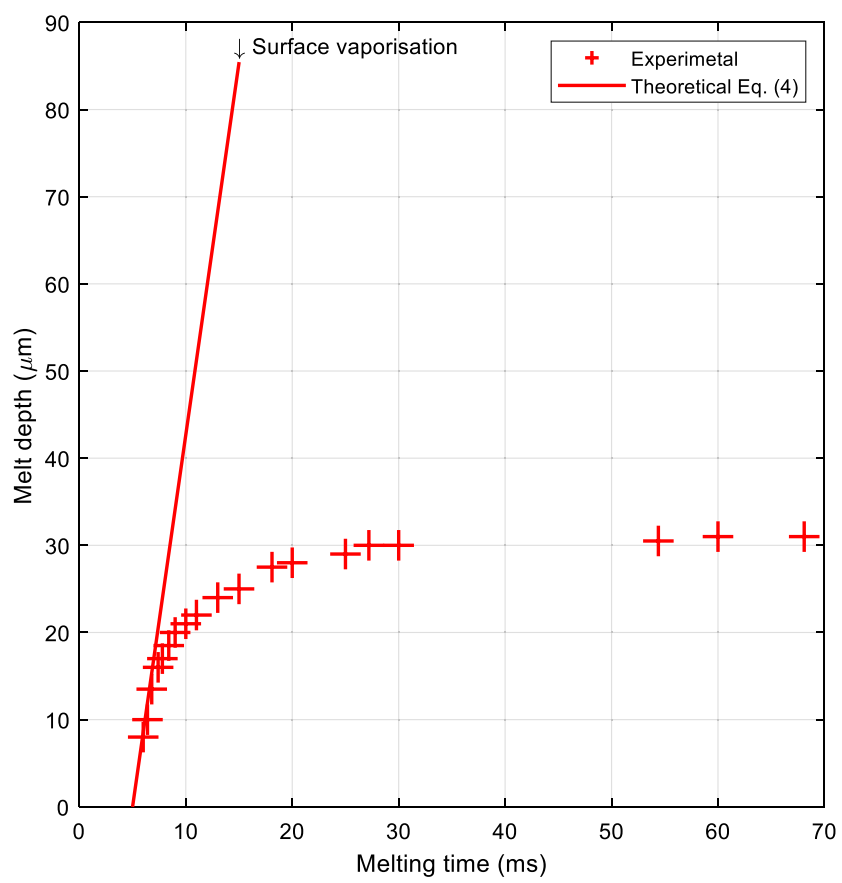

Fig. 3 Theory and experimental melt depths as a function of melting time 
results depart significantly from the linear theoretical trend when the melt pool depth increases beyond $20 \mu \mathrm{m}$. It is noted that Cohen's model is a one-dimensional model of uniform heating, and heat transfer is affected only by conduction. In this experiment, we have a Gaussian beam, and at $S>20 \mu \mathrm{m}$, the melt depth is a significant proportion of the beam radius $(w=131 \mu \mathrm{m})$. Consequently, we can expect flow generated by surface tension-driven convection known as the Marangoni effect, with a small contribution from the buoyancy force [40] and more efficient heat transfer the heat from the centre to the edge [41]. Figure 4 illustrates cross-sections of the solidified melt pools obtained at low $(9 \mathrm{~ms})$ and high $(27.2 \mathrm{~ms})$ interaction times. A relatively flat surface can be seen at low interaction times, whereas a significant change to the melt surface cross-sectional shape can be seen at $13.6 \mathrm{~ms}$ (and beyond). This suggests that the process at this point closely resembles the uniform model of conduction limited melting defined by Cohen.

It is clear from Fig. 3 that optimum efficiency does not occur at maximum melt-depth. In order to find this optimum, we calculate the specific energy required for melting, $E_{\text {melt_exp }}$, for the range of experimental interaction times $t_{\text {exp }}$ 6 to $68.1 \mathrm{~ms}$ defined such that,

$E_{\text {melt_exp }}=\frac{I_{0} t_{\text {exp }}}{z \rho}$

where $z$ is the maximum experimental melt depth.

Noting that the energy absorbed by the surface after time, $t$, by the laser is, $E=I A t$, after manipulation of Eqs. (4), (5), and (7) from Cohen's analysis we find, the specific energy required to melt material $E_{\text {melt theory }}$ is given by Eq. (15) and presented with $E_{\text {melt_exp }}$ in Fig. 5.
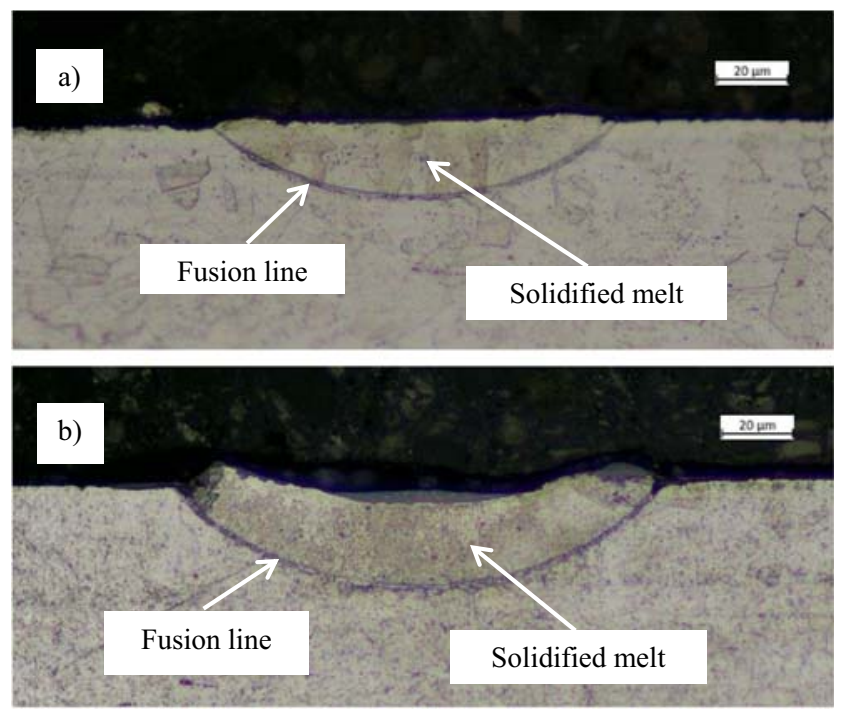

Fig. 4 Optical micrograph cross-section of melting only without ejection at $\mathbf{a}$ 9-ms and b 27.2-ms melting times with maximum melt depth of 20 and $30 \mu \mathrm{m}$, respectively

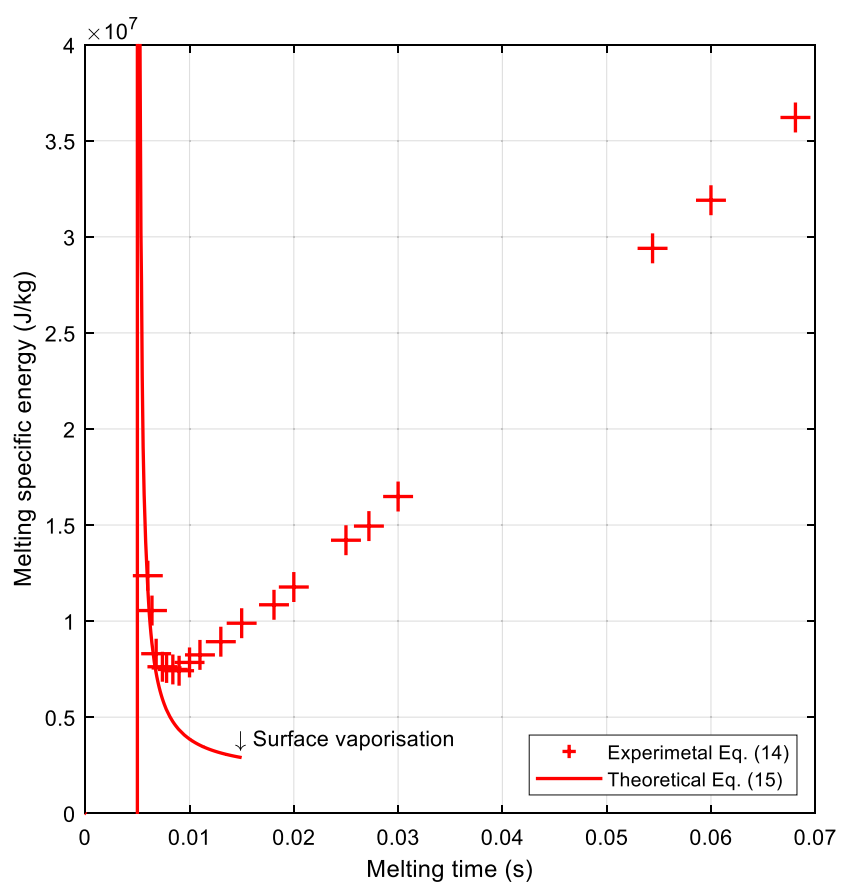

Fig. 5 Comparing experimental and theoretical results of melting process only specific energy as a function of melting time

$E_{\text {melt_theory }}=7.14 L_{\mathrm{m}} \frac{t}{\left(t-t_{\mathrm{m}}\right)}$

Figure 5 shows that the lowest specific energy is observed at $9 \mathrm{~ms}$, not $15 \mathrm{~ms}$, as Cohen's analysis predicts. At this value, the melt depth is approximately $20 \mu \mathrm{m}$ and was used for the DLM comparison explained in section 4.3.

\subsection{Effect of ejection pulse without melting}

The effect of only the ejection laser, without pre-laser melting, was observed. The experiment was conducted using a single pulse at $50 \mathrm{~mJ}$ energy on the workpiece at room temperature as shown in the 3D surface profiles in Fig. 6. Small features are created with depths less than $3.5 \mu \mathrm{m}$. It is evident from the profile that the nanosecond pulse alone does not remove a significant amount of material. However, as will be shown in the next section, the same pulse applied to a melt pool is sufficient to remove most of the molten material.

\subsection{Dual laser micromachining}

The DLM process was used to eject material at eight experimental melting times in the range of 9-60 ms, this is a reduced sample within the suitable melting time range identified in section 4.1. The ejection laser pulse was maintained at $50 \mathrm{~mJ}$ and laser fluence of $53 \mathrm{~J} / \mathrm{cm}^{2}$. Figure 7 gives result for the different melting times, melt depth, hole depth by 
Fig. 6 3D surface profile shows the effect of only the nanosecond ejection pulse of the Nd:YAG laser

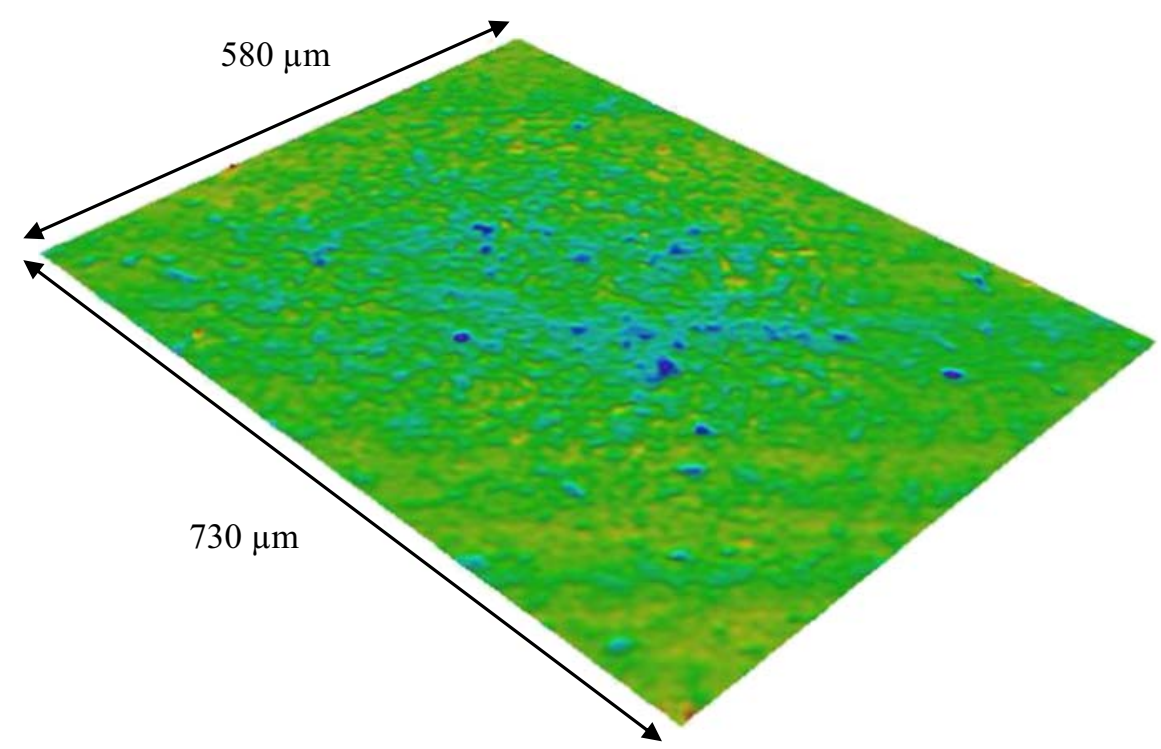

DLM, and the residual melt thickness. The combined DLM method created holes with 18-28- $\mu$ m maximum depth range; four repeats were made of each DLM melt time to calculate the mean.

3D surface profiles of the DLM holes were generated using the Alicona Infinite-Focus. The profiles were used to measure the depth of the holes. The maximum hole depth is used in the calculation of the removed mass. Figure 8 shows 3D images of the hole created at 9-ms melting time. The 3D image shows that the molten material was ejected by the effect of molten pool surface vaporisation using the nanosecond pulse, with a

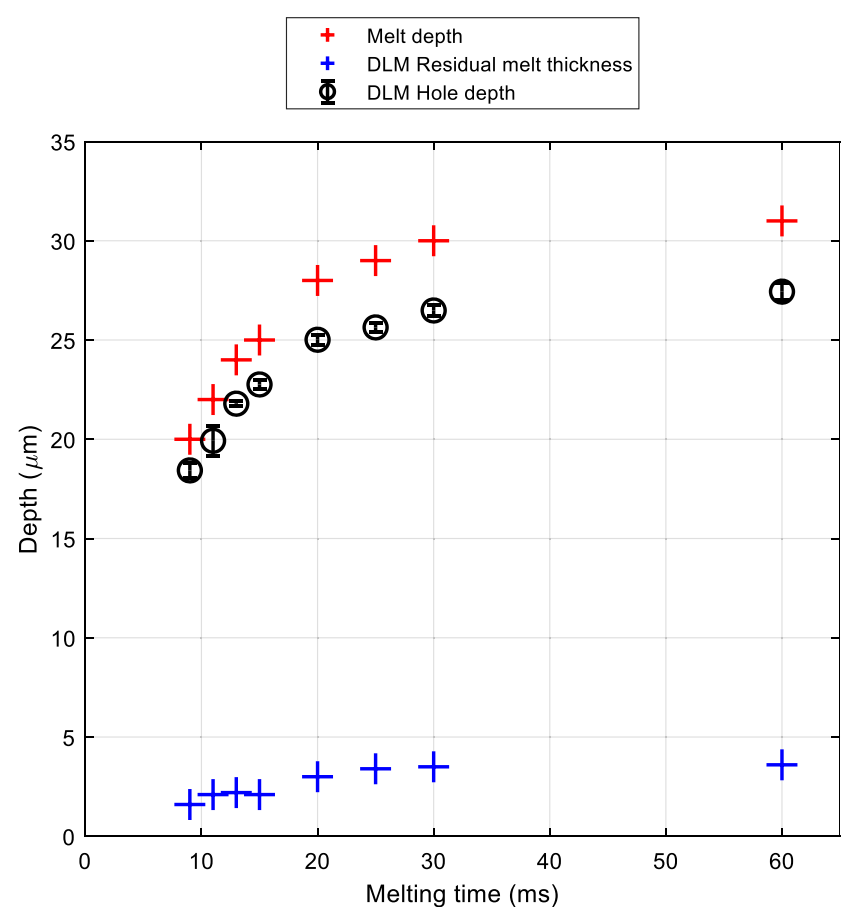

Fig. 7 Comparison of the relative changes in melt depth, DLM hole depth, and residual melt thickness with increasing melting time small amount of redeposited material at the workpiece surface along the periphery of the created hole.

Cross-sectional images of the DLM hole, created at 9-ms melting time, are shown in Fig. 9. This figure provides additional evidence of clean material ejection to the $3 \mathrm{D}$ surface profiles. There is a small amount of deposition of material at the edges of the features as would be expected by existing quasi-steady-state liquid ejection models of these types of processes [42, 43]. However, there is an increase in the residual molten material that not ejected as melt depth increases.

Analysis of the material quality shows that the DLM holes were found free from microcracks and with little redeposited material on the surface. Moreover, the micrographs show low porosity in the solidified molten material.

\section{Discussion}

The specific energy of experimental DLM results was calculated from the sum of the specific energy by a CW laser for the melting duration and the single ejection pulse given by,

$E_{\text {total_exp }}=\frac{I t+I_{\text {absorbed_eject }} t_{\text {eject }}}{\rho l}$

where $l$ is the maximum DLM hole depth, $t_{\text {eject }}$ is the ejection pulse duration, and $I_{\text {absorbed_eject }}$ is the absorbed irradiance of the ejection beam. $I_{\text {absorbed_eject }}=\left(1-r_{\text {eject }}\right) I_{\text {eject }}$, where $I_{\text {eject }}$ is the irradiance of the ejection beam and $r_{\text {eject }}$ is the reflection coefficient of ejection laser.

The mass of removed material in the DLM method was calculated by multiplying the material density by the volume of the hole with depth, $l$, by a small area of $0.5-\mu m$ radius at the centre of laser beam under the peak irradiance. 
Fig. 8 3D surface profile of the DLM method at 9-ms melting time

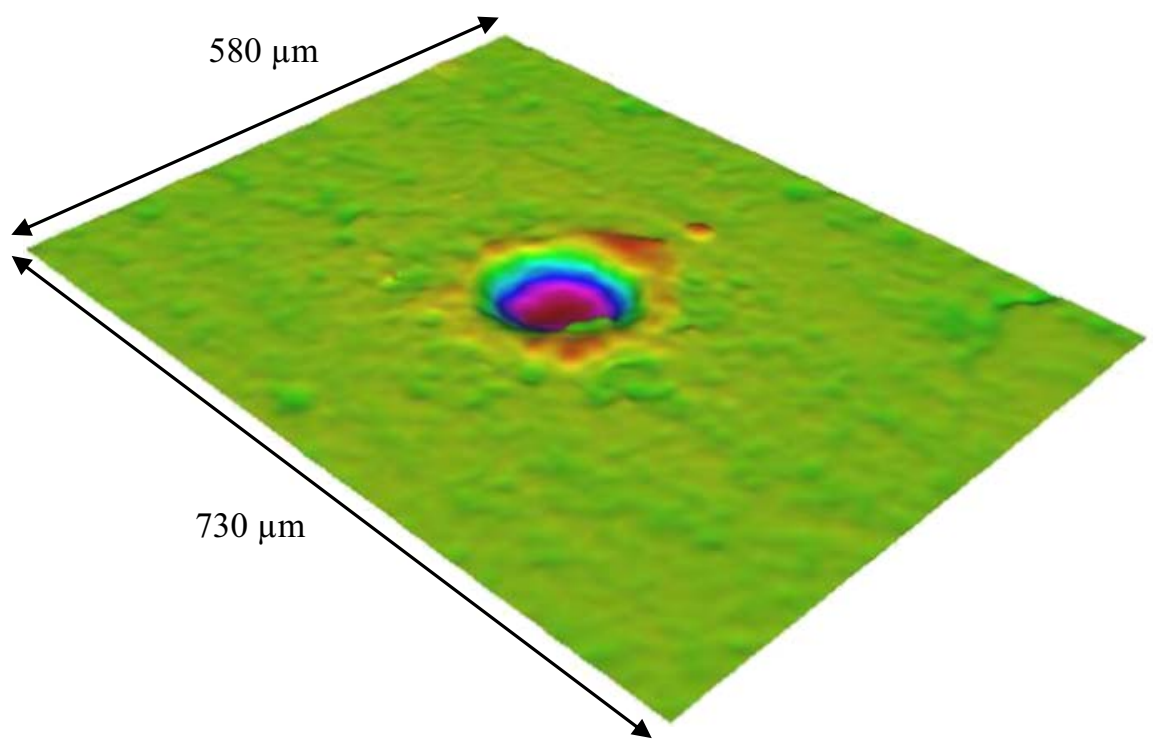

The results from the theoretical lossless vaporisation model Eq. (1), DLM theoretical model $E_{\text {melt }}$ Eq. (7) plus $E_{\text {eject }}$ in Eq. (10), experimental DLM results in Eq.(16), and the conventional processing results from Gay et al. [33] and Herfurth et al. [32] are shown in Fig. 10. The figure shows the material removal mass $(\mathrm{kg})$ against the energy $(\mathrm{J})$.

At the most efficient melting time of $9 \mathrm{~ms}$, the total energy absorbed by the workpiece in the DLM process was $9.73 \times$ $10^{-7} \mathrm{~J}$ and the mean mass ejected by the DLM process was $1.15 \times 10^{-13} \pm 2.66 \times 10^{-15} \mathrm{~kg}$ giving specific energy of $8.46 \times 10^{6} \pm 2 \times 10^{5} \mathrm{~J} / \mathrm{kg}$. Of the total energy in the optimised DLM process, $95 \%$ of the energy was delivered in the melting process and $5 \%$ in the ejection.

This result compares favourably with other researchers who have studied the removal of material conventionally from 304 stainless steel via vaporisation processes. In conventional vaporisation ablation, the material removal energy is dominated by the energy required to vaporise the material.

Work done by Gay et al. [33] used different pulse characteristics to improve the material removal per unit energy of similar material (304 stainless steel) using $4.4 \mu \mathrm{J}$ in 30 -ns pulse time scale at peak irradiance of $140 \mathrm{MW} / \mathrm{cm}^{2}$ and a repetition rate of $200 \mathrm{kHz}$. The results of the micro-milling experiment in terms of material removal mass per unit energy

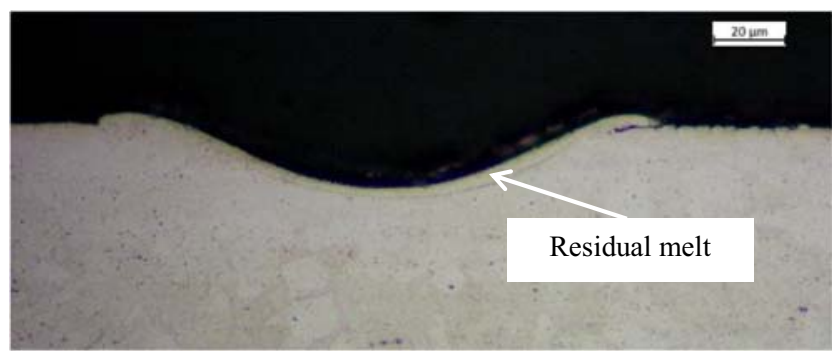

Fig. 9 Micrograph cross-section of the hole created by the DLM method at 9-ms melting time with a maximum hole depth of $18 \mu \mathrm{m}$ were calculated and are also presented in Fig. 10. Although the data of material removal efficiency does not state the reflectivity, the reflectivity for 304 stainless steel $\approx \approx 0.5$ at $1064 \mathrm{~nm}$ ) that is stated was used to calculate the absorbed energy. The mean specific energy was found to be $6.33 \times$ $10^{7} \pm 1.1 \times 10^{7} \mathrm{~J} / \mathrm{kg}$.

Herfurth et al. [32] established optimal processing parameters for different materials which include 304 stainless steel by milling $1.8 \times 1.8 \mathrm{~mm}$ squares into the surface. A nanosecond MOPA-based fibre laser was used with a wavelength of $1064 \mathrm{~nm}$, pulse duration ranging from 20 to $640 \mathrm{~ns}$, maximum

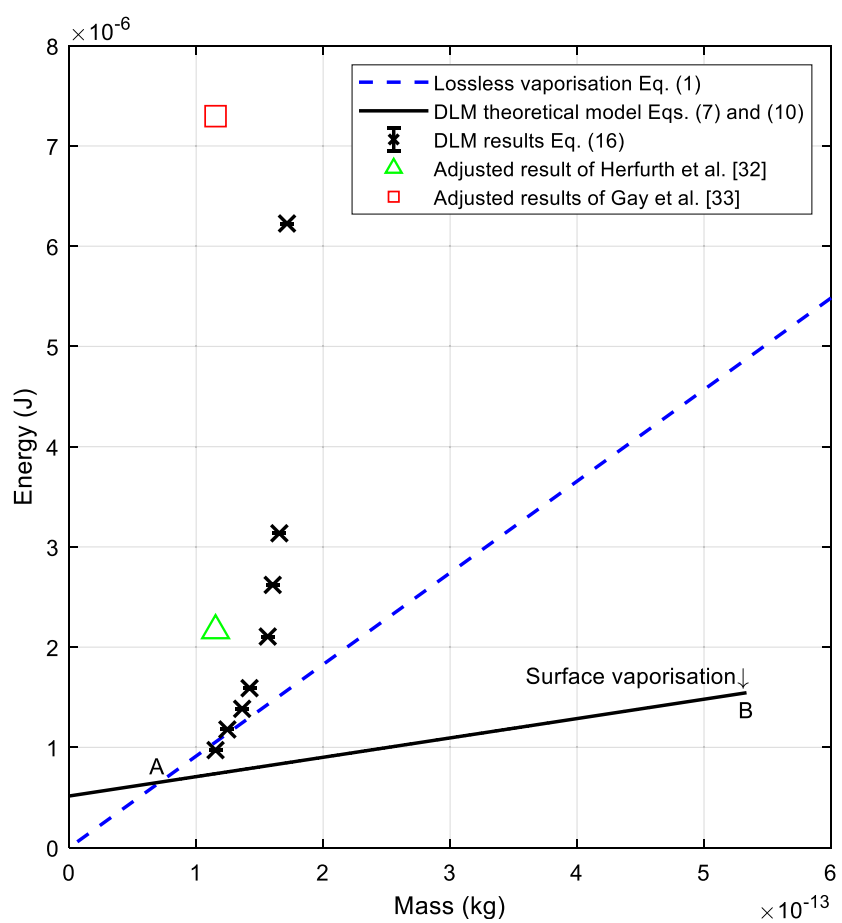

Fig. 10 Comparison of DLM and conventional processing energy efficiency 
pulse energy $0.5 \mathrm{~mJ}$, average intensity of $44.2 \mathrm{MW} / \mathrm{cm}^{2}$ and different pulses overlap percentages that governed by the spot diameter of 25 and $45 \mu \mathrm{m}$, the scanning speeds of 100 to $800 \mathrm{~mm} / \mathrm{s}$, and pulse repetition rates of 20 to $100 \mathrm{kHz}$. The highest material removal efficiency was found at $20-\mathrm{kHz}$ repetition rate, 320-ns pulse duration, and $150-\mathrm{mm} / \mathrm{s}$ scanning speed. The same reflectivity (0.5) used in Gay et al. [33] is used to calculate the absorbed specific energy for the result of Herfurth et al. [32] to be $1.88 \times 10^{7} \mathrm{~J} / \mathrm{kg}$.

The theoretical model of the lossless vaporisation presented in Fig. 10 is used to describe the energy required for mass removal by direct vaporisation (ablation). The curve is presented for our material 316 stainless steel and the 304 stainless steel despite a slight difference in the material properties. This lossless vaporisation curve was compared with the results from literature of Herfurth et al. [32] and Gay et al. [33].

It is clear from Fig. 10 that there is a significant difference in specific energy between these processes from literature. This may be justified by the difference in the laser irradiance that determines the dominant mechanism to be vaporisation or melt ejection [44]. For the same laser milling process and the same material, Herfurth et al. [32] used laser irradiance less than Gay et al. [33]. Other parameters play an important role in the material removal efficiency such as frequency, scanning speed, and pulse duration [32, 33].

The DLM result at the most efficient melting time, $9 \mathrm{~ms}$, was compared with the results from the literature to show the improvement in the material removal efficiency that this work aims to achieve. All the results of Herfurth et al. [32] and Gay et al. [33] were presented for the same removed mass of DLM method at melting time $9 \mathrm{~ms}$ to make a clear comparison. It is shown in Fig. 10. that the energy used in DLM is $45 \%$ of the energy used by Herfurth et al., [32] and 13\% of the energy used by Gay et al. [33], to remove the same mass.

\section{Further work}

This work shows that the nanosecond pulse used can achieve the impulse required for ejection in the models of Robin and Nordin [42] and Shui [43]. The calculations presented have also been able to calculate the optimum melting energy and ejection pulse duration hypothesised by Lehane and Kwok [24].

Robin and Nordin [42] investigated theoretically the initial experiment conducted by Fox [23] to calculate the minimum impulse required to eject the molten material. In Robin and Nordin's model, it is assumed that the molten material is ejected from the irradiated surface as an annular flow, with thickness one-tenth of the hole radius. It also assumed that the molten material at the surface is thin enough to be ejected by the pulsed laser and the material is accelerated to its terminal velocity during the pulse time. The material is ejected by the effect of recoil pressure from the melt pool sides [42, 43] generated during the rapid vaporisation of a thin layer of the molten liquid using the second pulsed laser [24].

Their required threshold was $2 \times 10^{-5} \mathrm{~N} \cdot \mathrm{s}$ for melt layer ejection of aluminium. Microsecond duration laser pulses, with intensities higher than $10^{8} \mathrm{~W} / \mathrm{cm}^{2}$, can generate impulses 10 to $12 \times 10^{-3} \mathrm{~N} \cdot \mathrm{s}$ [45] which greatly exceed this minimum threshold. The impulse response of different materials is not considered to be significant [46]. As shown in the experimental results, the short pulses have enough energy to eject the molten material.

However, in the case presented in this paper, the ejection laser pulse is significantly larger than the melt pool and could be considered as a uniform distribution of energy over the melt pool, restricting the annular flow of Robin and Nordin. Recent work by Yuan et al. [47] has shown material ejection in cases where the ejection pulse diameter is both smaller and larger than the melt pool diameter. Yuan et al.'s results are consistent with our own where there is no significant redeposition of recast material at the hole edge.

While this paper presents the results of a more efficient material ejection process, it does not fully explain the physical mechanism for the ejection process. There is still uncertainty in the ejection models $[42,43]$ as they both assume the material is ejected during the laser beam interaction time and the molten material is ejected from the melt pool periphery without considering the pressure gradient along the distance from the melt pool centre. It is suggested that further work is conducted into studying the effects of the shockwave pressure created by rapid surface vaporisation.

\section{Conclusion}

This paper presents a combined analysis of an energy model and experimental data for the first time in this field. It has also directly compared the energy efficiency of this process with conventional machining and shown evidence of clean material removal. Two lasers were used in this study, a continuous wave laser to create a molten pool with melt depths from 8 to $31 \mu \mathrm{m}$, while a nanosecond pulse laser was used to eject the molten material by vaporising the molten pool surface to generate recoil pressure. Theoretical calculations were performed for the melt pool size against the melting process and compared with the experimental melt depths. The highest melting efficiency was found at 9-ms melting time, generating $20-\mu \mathrm{m}$ melt depth. The pulsed laser was applied on the molten pool surface in the DLM method resulting in an ejection of $90 \%$ of the molten material. This created holes in the surface of 316 stainless steel at a specific energy of $8.46 \times 10^{6} \mathrm{~J} / \mathrm{kg}$. The theoretical models of melting energy presented were used to identify that total energy used in 
the DLM process was $95 \%$ melting and $5 \%$ for ejection. It was also shown that there would be a theoretical reduction in total energy consumption of 3 times comparing DLM with vaporisation machining. This was confirmed by comparing the DLM results of this paper with conventional laser processing found in the literature. The results showed that the method presented can increase material removal efficiency compared with the conventional processes by approximately 2 to 8 times.

Compliance with ethical standards The authors declare that they have no conflict of interest.

Open Access This article is licensed under a Creative Commons Attribution 4.0 International License, which permits use, sharing, adaptation, distribution and reproduction in any medium or format, as long as you give appropriate credit to the original author(s) and the source, provide a link to the Creative Commons licence, and indicate if changes were made. The images or other third party material in this article are included in the article's Creative Commons licence, unless indicated otherwise in a credit line to the material. If material is not included in the article's Creative Commons licence and your intended use is not permitted by statutory regulation or exceeds the permitted use, you will need to obtain permission directly from the copyright holder. To view a copy of this licence, visit http://creativecommons.org/licenses/by/4.0/.

\section{References}

1. Mishra S, Yadava V (2015) Laser beam micromachining (LBMM) - a review. Opt Lasers Eng 73:89-122

2. Dubey AK, Yadava V (2008) Laser beam machining-a review. Int J Mach Tools Manuf 48(6):609-628

3. Sheng PS, Joshi VS (1995) Analysis of heat-affected zone formation for laser cutting of stainless steel. J Mater Process Technol 53(3-4):879-892

4. Madic M, Radovanovic M (2012) Analysis of the heat affected zone in CO2 laser cutting of stainless steel. Therm Sci 16(suppl. 2):363-373

5. Fu CH, Liu JF, Guo A (2015) Statistical characteristics of surface integrity by fiber laser cutting of Nitinol vascular stents. Appl Surf Sci 353:291-299

6. Genna S, Leone C, Lopresto V, Santo L, Trovalusci F (2010) Study of fibre laser machining of $\mathrm{C} 45$ steel: influence of process parameters on material removal rate and roughness. Int J Mater Form 3(S1):1115-1118

7. Teixidor D, Ferrer I, Ciurana J, Özel T (2013) Optimization of process parameters for pulsed laser milling of micro-channels on AISI H13 tool steel. Robot Comput Integr Manuf 29(1):209-218

8. Leitz K-HH, Redlingshöer B, Reg Y, Otto A, Schmidt M (2011) Metal ablation with short and ultrashort laser pulses. Phys Procedia 12(PART 2):230-238

9. Le Harzic R et al (2005) Pulse width and energy influence on laser micromachining of metals in a range of 100 fs to $5 \mathrm{ps}$. Appl Surf Sci 249(1-4):322-331

10. Farooq K, Kar A (1998) Removal of laser-melted material with an assist gas. J Appl Phys 83(12):7467-7473

11. Tangwarodomnukun V, Wang J, Huang CZ, Zhu HT (2014) Heating and material removal process in hybrid laser-waterjet ablation of silicon substrates. Int J Mach Tools Manuf 79:1-16
12. Ahn D, Seo C, Kim D (2012) "Removal of metals and ceramics by combined effects of micro liquid jet and laser pulse," J Appl Phys, vol. 112 , no. 12

13. López López JM, Bakrania A, Coupland J, Marimuthu S (2016) Droplet assisted laser micromachining of hard ceramics. J Eur Ceram Soc 36(11):2689-2694

14. Kruusing A (2004) Underwater and water-assisted laser processing: part 2 - etching, cutting and rarely used methods. Opt Lasers Eng 41(2):329-352

15. Li L, Achara C (2004) Chemical assisted laser machining for the minimisation of recast and heat affected zone. CIRP Ann Manuf Technol 53(1):175-178

16. Ghany KA, Newishy M (2005) Cutting of $1.2 \mathrm{~mm}$ thick austenitic stainless steel sheet using pulsed and CW Nd:YAG laser. J Mater Process Technol 168(3):438-447

17. Muhammad N, Whitehead D, Boor A, Li L (2010) Comparison of dry and wet fibre laser profile cutting of thin $316 \mathrm{~L}$ stainless steel tubes for medical device applications. J Mater Process Technol 210(15):2261-2267

18. Li L, Diver C, Atkinson J, Giedl-Wagner R, Helml HJ (2006) Sequential laser and EDM micro-drilling for next generation fuel injection nozzle manufacture. CIRP Ann Manuf Technol 55(1): 179-182

19. Steen WM, Mazumder J (2010) Laser material processing, 4th ed. springer science \& business media, New York

20. French PW, Naeem M, Sharp M, Watkins KG (2006) Investigation into the influence of pulse shaping on drilling efficiency. International Congress on Applications of Lasers \& ElectroOptics 99(310):166-172

21. Markcoons DJW, Voisey KT (2018) An investigation to determine if the laser drilling capabilities of a $2 \mathrm{~kW}$ fibre laser can be enhanced using pulse train shaping. Lasers Eng 39(0):17-33

22. Low DKY, Li L, Byrd PJ (2001) The influence of temporal pulse train modulation during laser percussion drilling. Opt Lasers Eng 35(3):149-164

23. Fox JA (1975) A method for improving continuous wave laser penetration of metal targets. Appl Phys Lett 26(12):682-684

24. Lehane C, Kwok HSS (2001) Enhanced drilling using a dual-pulse Nd:YAG laser. Appl Phys A Mater Sci Process 73(1):45-48

25. Walther K, Brajdic M, Kreutz EW (2008) Enhanced processing speed in laser drilling of stainless steel by spatially and temporally superposed pulsed Nd:YAG laser radiation. Int J Adv Manuf Technol 35(9-10):895-899

26. Wang Z, Qin Y, Yang S, Shi B, Wang H, Chen H (2017) Material removal during double-pulsed ( $\mathrm{ms}$ and $\mathrm{ns}$ ) laser drilling. Fourth Int Symp Laser Interact Matter 10173(May): 1017324

27. Leibowitz L et al. (1976) "Properties for LMFBR safety analysis," Argonne, Illinois

28. Su Y, Li Z, Mills KC (2005) Equation to estimate the surface tensions of stainless steels. J Mater Sci 40(9-10):2201-2205

29. Cohen MI (1967) Melting of a half-space subjected to a constant heat input. J Frankl Inst 283(4):271-285

30. Xie J, Kar A (1997) Mathematical modeling of melting during laser materials processing. J Appl Phys 81(7):3015-3022

31. Knight CJ (1979) Theoretical modeling of rapid surface vaporization with back pressure. AIAA J 17(5):519-523

32. Herfurth H, Patwa R, Lauterborn T, Heinemann S, Pantsar H (2007) "Micromachining with tailored nanosecond pulses," no. October 2007, p. $67961 \mathrm{G}$

33. Gay D et al. (2009) "Micro-milling process improvement using an agile pulse-shaping fiber laser," in Proc. SPIE 7386

34. Sun Z, Ion JC (1995) Laser welding of dissimilar metal combinations. J Mater Sci 30(17):4205-4214

35. $\mathrm{Xu} \mathrm{X} \mathrm{(2002)} \mathrm{Phase} \mathrm{explosion} \mathrm{and} \mathrm{its} \mathrm{time} \mathrm{lag} \mathrm{in} \mathrm{nanosecond} \mathrm{laser}$ ablation. Appl Surf Sci 197-198:61-66 
36. William M (2010) Steen and Jyotirmoy Mazumder. In: Laser material processing, 2nd ed. Springer-Verlag Berlin and Heidelberg $\mathrm{GmbH} \&$ Co. K, New York

37. Bergstrom D, Powell J, Kaplan AFH (2007) The absorptance of steels to Nd: YLF and Nd : YAG laser light at room temperature. Appl Surf Sci 253(11):5017-5028

38. Xie J, Kar A, Rothenflue JA, Latham WP (1997) Temperaturedependent absorptivity and cutting capability of $\mathrm{CO} 2, \mathrm{Nd}$ :YAG and chemical oxygen-iodine lasers. J Laser Appl 9(2):77

39. Ion JC (2005) "Laser processing of engineering materials: principles, procedure and industrial application," in Laser processing of engineering materials, Elsevier, p. 576

40. Basu S, DebRoy T (1992) Liquid metal expulsion during laser irradiation. J Appl Phys 72(8):3317-3322

41. Mazumder J (1991) Overview of melt dynamics in laser processing. Opt Eng 30(8):1208

42. Robin JE, Nordin P (1976) Improved cw laser penetration of solids using a superimposed pulsed laser. Appl Phys Lett 29(1):3-5
43. Shui VH (1978) Effect of induced pressure and impulse on cw laser penetration of solids. Phys Fluids 21(12):2174-2178

44. Chan CL, Mazumder J (1987) One-dimensional steady-state model for damage by vaporization and liquid expulsion due to lasermaterial interaction. J Appl Phys 62(11):4579-4586

45. Metz SA, Hettche LR, Stegman RL, Schriempf JT (1975) "Effect of beam intensity on target response to high intensity pulsed co2 laser Radiation," vol. 46, no. 4, pp. 1634-1642

46. Phipps CR et al (1988) Impulse coupling to targets in vacuum by $\mathrm{KrF}, \mathrm{HF}$, and CO2 single-pulse lasers. J Appl Phys 64(3):10831096

47. Yuan B-S, Zhang Y, Zhang W, Dong Y, Jin G-Y (2018) The effect of spot size combination mode on ablation morphology of aluminum alloy by millisecond-nanosecond combined-pulsel. Materials (Basel) 11(8):1419

Publisher's note Springer Nature remains neutral with regard to jurisdictional claims in published maps and institutional affiliations. 